Gut, 1983, 24, 7-10

\title{
Factors affecting gall-stone dissolution rate during chenic acid therapy
}

\author{
D P MAUDGAL, R M KUPFER, and T C NORTHFIELD \\ From the Norman Tanner Gastroenterology Unit, St James's Hospital, and Department of Medicine, St \\ George's Hospital Medical School, London
}

SUMMARY Gall-stone dissolution rate was measured in 52 patients with radiolucent gall stones in a functioning gall bladder receiving chenic acid $15 \mathrm{mg} / \mathrm{kg} /$ day. Percentage reduction in gall-stone area at six months was inversely related to initial gall-stone diameter $(n=52 ; r=-0.53 ; p<0 \cdot 001)$, and to cholesterol saturation index of fasting gall-bladder bile during treatment $(n=28 ; r=-0.61$; $\mathrm{p}<0.001$ ). The duration of treatment required for complete dissolution was directly related to initial gall-stone diameter $(r=0.47 ; \mathrm{p}<0.02)$. We conclude that the rate of gall-stone dissolution depends not only on gall-stone size but also on the degree of unsaturation of gall-bladder bile achieved during chenic acid treatment.

Certain prerequisites have been defined for the dissolution of gall stones in man. First, medical treatment with chenodeoxycholic (chenic) acid is effective only for cholesterol gall stones. ${ }^{1}$ These can be identified clinically as radiolucent stones on oral cholecystogram, ${ }^{2}$ but 10 to $20 \%$ of radiolucent stones do not respond to medical treatment, and turn out at operation to be pigment stones. Secondly, opacification of the gall bladder must be observed at oral cholecystogram, ${ }^{3}$ as failure of the radio-opaque dye to enter the gall bladder predicts failure of unsaturated bile to enter the gall bladder. Thirdly, fasting gall-bladder bile should become unsaturated with cholesterol during treatment; ${ }^{3}$ obese patients ${ }^{4}$ may require a higher dose to achieve this.

The effect of the degree of unsaturation of gall-bladder bile on the rate of gall-stone dissolution in man is not known. Although it can be predicted on theoretical grounds that small cholesterol gall stones will dissolve faster than large ones because of the high surface area to volume ratio, ${ }^{5}$ this relationship has also not been studied quantitatively in man.

We assessed gall-stone dissolution rate during six months' treatment with chenic acid in 52 patients with radiolucent gall stones. We studied the effect of initial gall-stone size, and of saturation index of

Address for reprint requests: Dr T C Northfield, Department of Medicine, St George's Hospital Medical School, Cranmer Terrace, London SW17 ORE, UK.

Received for publication 7 April 1982 fasting gall-bladder bile during treatment, on gallstone dissolution rate.

\section{Methods}

\section{PATIENTS}

Fifty-two patients were studied; 16 were men and 36 women, aged 18 to 85 years (mean age 54 years). All patients had radiolucent gall stones in a gall bladder that opacified well on oral cholecystogram carried out within two weeks before starting treatment with oral chenic acid $(15 \mathrm{mg} / \mathrm{kg} /$ day $)$. Written informed consent was obtained from each patient before entering the study, which was approved by the local hospital ethical committee.

\section{GALL-STONE DISSOLUTION RATE}

For the purpose of this study, we have defined gall-stone dissolution rate as the percentage change in gall-stone area of the largest gall stone during the first six months of treatment. This was measured by a grid system from two oral cholecystograms carried out immediately before and at six months after starting treatment with chenic acid. All gall-stone area measurements from consecutive oral cholecystograms were made by someone who was not connected with this study. In order to validate the method, the area of the same stone was assessed cholecystographically before and after a fatty meal during which the orientation of the stone was likely to change. Good agreement between the two area measurements was found (coefficient of variation 
$11 \%) .{ }^{6}$ We have also demonstrated that gall-stone area measured by this technique and its volume measured in vitro by water displacement after operative removal of gall stones correspond closely to the calculated curve for the relationship between area and volume. ${ }^{6}$ Cholecystograms were carefully standardised so that the angulation of the patient and the distance between the $x$-ray tube and plate were identical on both occasions.

\section{COMPLETE GALL-STONE DISSOLUTION}

This was defined as absence of gall stones on oral cholecystogram, carried out at six monthly intervals, and confirmed by second negative cholecystogram after a further three months' treatment. In nine patients, gall-stone dissolution was also checked by ultrasound carried out by a consultant unaware of the $x$-ray findings. In all nine cases ultrasound showed no evidence of gall stones.

\section{BILIARY LIPID ANALYSIS}

Fasting gall-bladder bile samples for measurement of saturation index were obtained by nasoduodenal intubation and aspiration of bile rich duodenal fluid during intravenous infusion of cholecystokinin (Boots Ltd). Bile samples were obtained before and at least six weeks after starting treatment with chenic acid, as bile lipid composition has been shown to become constant within four weeks after starting treatment with chenic acid. ${ }^{7}$ Total bile acid concentration was measured by the $3 \alpha-$ hydroxysteroid dehydrogenase enzyme assay as described by Talalay ${ }^{8}$ and modified by Admirand and Small. ${ }^{9}$ Phospholipids were measured by the method of Bartlett ${ }^{10}$ and cholesterol was measured by the cholesterol oxidase method ${ }^{11}$ in an aliquot of bile that was diluted at the bedside in isopropanol (1 in 10). Saturation index was calculated using the polynomial equation developed by Thomas and Hofmann, ${ }^{12}$ based on the limits of cholesterol solubility described by Hegardt and $\mathrm{Dam}^{13}$ and Holzbach et al. ${ }^{14}$

\section{Results}

GALL-STONE SIZE AND DISSOLUTION RATE (Fig. 1) Initial gall-stone size was assessed from the diameter of the largest stone in the patient's gall bladder, and varied between 2 and $27 \mathrm{~mm}$. There was a significant inverse relationship between initial diameter and percentage reduction in area of the largest gall stone at six months $(n=52 ; r=0.53 ; p<0.001)$. At six months six out of 13 patients with an initial gall-stone diameter of more than $15 \mathrm{~mm}$ showed definite evidence of dissolution, while 31 out of 39 patients with an initial stone diameter of $15 \mathrm{~mm}$ or

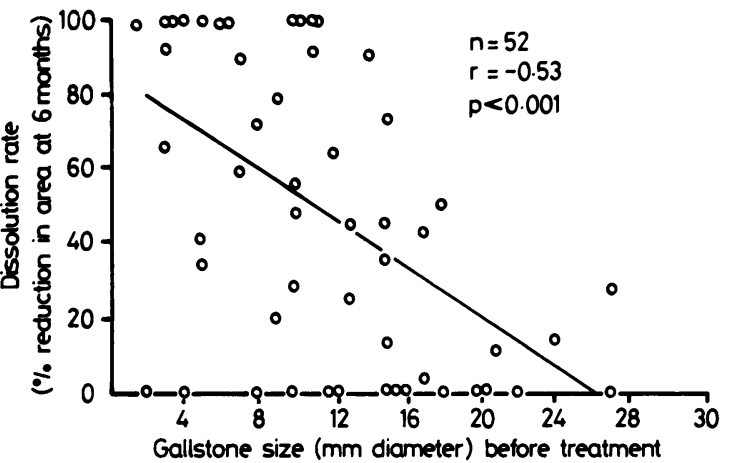

Fig. 1 Relationship between initial gall-stone size (diameter in $\mathrm{mm}$ ) and gall-stone dissolution rate (percentage reduction in gall-stone area) at six months during chronic acid treatment.

less showed definite evidence of dissolution $\left(\chi^{2}=5 \cdot 0\right.$; $\mathrm{p}<0.05)$.

\section{GALL-BLADDER BILE SATURATION INDEX AND} DISSOLUTION RATE (Fig. 2)

Twenty-eight of the 52 patients had cholesterol saturation index of fasting gall-bladder bile measured during treatment with chenic acid. There was an inverse relationship between saturation index and gall-stone dissolution rate $(n=28$; $r=-0.61 ; p<0.001)$. In only two of the 23 patients who showed definite evidence of gall-stone dissolution (more than 10\% reduction in gall-stone area after six months' treatment) was saturation index, measured six to eight weeks after starting treatment, more than $1(1.97$ and 1.08). In three of the five patients who did not show any reduction in gall-stone size saturation index was more than 1 $(1 \cdot 05,1 \cdot 11$, and $1 \cdot 16)$.

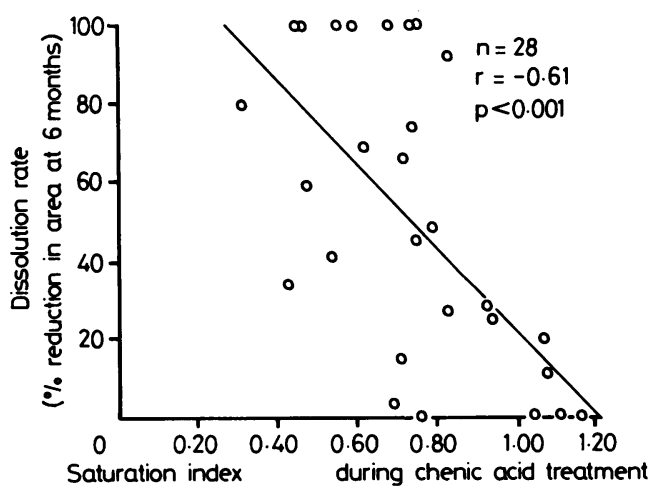

Fig. 2 Relationship between cholesterol saturation index and gall-stone dissolution rate. 
DURATION OF TREATMENT REQUIRED FOR COMPLETE DISSOLUTION

Twenty-four of the 45 patients followed for 42 months achieved complete gall-stone dissolution over this period. The duration of treatment required for complete dissolution was inversely related to percentage reduction in gall-stone area at six months, further confirming the validity of our method of assessing gall-stone dissolution rate (using Kendall's rank correlation $\tau=0.66, \mathrm{p}<0.001$ ). The duration of treatment required for complete dissolution was directly related to initial gall-stone size $(r=0.47, p<0.02)$. Complete dissolution occurred in four out of 13 patients with initial gall-stone diameter of $15 \mathrm{~mm}$ or more, and in 21 out of 39 with initial diameter of less than $15 \mathrm{~mm}$. In 15 of these, saturation index was measured during treatment. There was a tendency for duration of treatment required for complete gall-stone dissolution to be related to saturation index during treatment $(r=0.51)$, but the numbers were small and thus the correlation was not statistically significant. Partial dissolution at six months was of value in predicting complete dissolution in the 45 patients followed for 42 months. Twenty-three of the 31 patients showing partial dissolution at six months (decrease in gall-stone area of $10 \%$ or more) achieved complete dissolution during this period, compared with one out of 14 patients showing no definite dissolution at six months $\left(\chi^{2}=14.83\right.$; $\mathrm{p}<0.001)$.

\section{Discussion}

This study represents the first demonstration in man that gall-stone dissolution rate, assessed during the first six months of chenic acid therapy for radiolucent gall stones, is related to the degree of cholesterol unsaturation of fasting gall-bladder bile. We assessed cholesterol saturation at six to eight weeks after starting treatment, because Iser and colleagues $^{7}$ have shown that the degree of unsaturation reaches a maximum within the first month of treatment and remains constant thereafter. Our findings are consistent with the observation of Bell et al that the rate of dissolution of human gall stones in rhesus monkey bile is related to the cholesterol solubilising capacity of the bile. ${ }^{15}$ Thus, it is therapeutically worthwhile to aim at a very low saturation index during dissolution therapy.

We have also shown a quantitative relationship between initial gall-stone diameter and gall-stone dissolution rate during the first six months' treatment with chenic acid, thus confirming previous qualitative assessments. ${ }^{5}$ We measured initial gall- stone diameter because this is the conventional clinical method of describing gall-stone size. Because we measured percentage change in gallstone area over a six month period, we were able to detect partial dissolution of stones more than $15 \mathrm{~mm}$ in diameter, thus demonstrating that there is no fixed cut-off point in gall-stone size above which dissolution does not take place. Furthermore, four out of 13 patients with initial diameter of $15 \mathrm{~mm}$ or more achieved complete dissolution over 42 months. In patients having a medical contraindication to surgery, it is therefore unjustifiable to quote any arbitrary measurement of gall-stone size as a definite contraindication to medical treatment.

According to our definition, gall-stone dissolution rate is expressed as percentage change in gall-stone area of the largest gall stone over a six month period. As gall-stone size progressively diminishes during treatment, dissolution rate defined in this way will not remain constant from one month to another but will represent the average rate over the six month period, nor will it remain constant from one six month period to another. In patients with more than one stone, dissolution rate is not constant for all the stones. We expressed it in terms of the largest gall stone, as this is the one that is rate limiting for dissolution therapy.

These results indicate that patients should be matched for gall-stone size when comparing dissolution rates on different treatment regimens. Furthermore, when this is done, it is justifiable to assume that differences in saturation index are likely to be associated with differences in dissolution rate during the first six month treatment with different regimens designed to accelerate gall-stone dissolution rate on chenic acid therapy. We have confirmed previous reports that partial dissolution at six months is of value in predicting subsequent complete dissolution. ${ }^{1617}$

We are grateful to Weddel Pharmaceuticals for supplying chenodeoxycholic acid (Chendol) and providing financial support, to $\mathrm{Mr} \mathbf{R}$ Bird for technical assistance, and to Mrs Moya Gannon for nursing assistance.

\section{References}

1 Thistle JL, Hofmann AF. Efficacy and safety of chenodeoxycholic acid for dissolving gallstones. $N$ Engl J Med 1973; 289: 655-9.

2 Bell GD, Dowling RH, Whitney B, Sutor DJ. The value of radiology in predicting gallstone type when 
selecting patients for medical treatment. Gut 1975; 16: $359-64$.

3 Iser JH, Dowling RH, Mok HYI, Bell GD. Chenodeoxycholic acid treatment of gallstones - a follow-up report and analysis of factors influencing response to therapy. N Engl J Med 1975; 293: 378-83.

4 Iser JH, Maton PN, Murphy GM, Dowling RH. Resistance to chenodeoxycholic acid therapy. Treatment in obese patients with gallstones. $\mathrm{Br} \mathrm{Med} \mathrm{J}$ 1978; 1: 1509-12.

5 Small DM. Gallstones: diagnosis and treatment. Postgrad Med 1972; 51: 187-93.

6 Kupfer RM, Maudgal DP, Northfield TC. Gallstone dissolution rate during chenic acid therapy: effect of bedtime administration plus low cholesterol diet. Dig Dis Sci 1982. (September, 1982.)

7 Iser IH, Murphy GM, Dowling RH. Speed of change in biliary lipids and bile acids with chenodeoxycholic acid - is intermittent therapy feasible? Gut 1977; 18: 7-15.

8 Talalay P. Enzymatic analysis of steroid hormones. In: Glick D, ed. Methods of biochemical analysis. New York: New York Interscience, 1960: vol 8, 119.

9 Admirand WH, Small DM. The physico-chemical basis of cholesterol gallstone formation in man. J Clin Invest 1968; 47: 1045-52.
10 Bartlett GR. Phosphorous assay in column chromatography. J Biol Chem 1959; 234: 466-8.

11 Roda A, Festi D, Sauna C, et al. Enzymatic determination of cholesterol in bile. Clin Chim Acta 1975; 64: 337-49.

12 Thomas PJ, Hofmann AF. A simple calculation of lithogenic index of bile. Experimental biliary lipid composition on rectangular coordinates. Gastroenterology 1973; 65: 698-700.

13 Hegardt FG, Dam H. The solubility of cholesterol in aqueous solution of bile salts and lecithin. $Z$ Ernahrungswiss 1971; 10: 223-33.

14 Holzbach RT, Marsh M, Olszewski M, Holan K. Cholesterol solubility in bile: evidence that supersaturated bile is frequent in healthy man. $J$ Clin Invest 1973; 52: 1467-79.

15 Bell GD, Sutor DJ, Whitney B, Dowling RH. Factors influencing human gallstone dissolution in monkey, dog and human bile. Gut 1972; 13: A856 (abstract).

16 Thistle JL, Hofmann AF, Ott BJ, Stephens DH. Chenotherapy for gallstone dissolution. I. Efficacy and safety. JAMA 1978; 239: 1041-6.

17 Bateson MC, Trash DB, Bouchier IAD. Can six-month cholecystogram predict eventual response to gallstone dissolution Gut 1980; 21: A443 (abstract). 